This item was submitted to Loughborough's Research Repository by the author.

Items in Figshare are protected by copyright, with all rights reserved, unless otherwise indicated.

\title{
Impact of wind curtailment and storage on the Irish power system 2020 renewable electricity targets: a free open-source electricity system balancing and market (ESBM) model
}

\section{PLEASE CITE THE PUBLISHED VERSION}

\section{PUBLISHER}

IET (c) the authors

\section{VERSION}

AM (Accepted Manuscript)

\section{PUBLISHER STATEMENT}

This work is made available according to the conditions of the Creative Commons Attribution-NonCommercialNoDerivatives 4.0 International (CC BY-NC-ND 4.0) licence. Full details of this licence are available at: https://creativecommons.org/licenses/by-nc-nd/4.0/

\section{LICENCE}

CC BY-NC-ND 4.0

\section{REPOSITORY RECORD}

McKenna, Eoghan, and Murray Thomson. 2019. "Impact of Wind Curtailment and Storage on the Irish Power System 2020 Renewable Electricity Targets: A Free Open-source Electricity System Balancing and Market (ESBM) Model". figshare. https://hdl.handle.net/2134/15962. 


\title{
Impact of wind curtailment and storage on the Irish power system 2020 renewable electricity targets: a free open-source electricity system balancing and market (ESBM) model
}

\author{
E J McKenna*, M Thomson \\ Centre for Renewable Energy Systems Technology (CREST), \\ School of Electronic, Electrical and Systems Engineering, \\ Loughborough University, Loughborough, LE11 3TU, UK \\ *Corresponding author: e.j.mckenna@lboro.ac.uk
}

Keywords: wind power; curtailment; Ireland; storage; model.

\begin{abstract}
The All-island power system, representing the electrical grids of the Republic of Ireland and Northern Ireland, has a target of supplying $37 \%$ of electricity with wind power by 2020 . This presents a considerable integration challenge, in particular associated with the increasing number of periods when there is too much wind power and not enough demand on the system, requiring wind power to be turned off or 'curtailed'.
\end{abstract}

The authors previously estimated potential curtailment on the All-island system in 2020 using a novel model. The model was validated using actual wind output and curtailment data from 2011, and produced results for 2020 indicating curtailment levels ranging from $5.6 \%$ to $8.5 \%$ consistent with previously published estimates.

This paper expands the previously published model to include: simulation of dispatch of conventional generation based on merit order; a representation of variable prices within a wholesale electricity market; and the operation of electrical energy storage within the system. The model is used to estimate the installed wind capacity required to supply $37 \%$ of electrical demand and the potential for storage to reduce the capacity required to meet this target. Finally, the model has been adapted to MS Excel and made available to download for free.

\section{Introduction}

A challenge of integrating high penetrations of wind power is managing periods when system demand is low and there is too much wind generation. When this occurs at the national level, it can be necessary to turn down, or 'curtail' wind power. When wind power is turned down due to local network congestion this is known as a 'constraint'. Collectively, curtailment and constraints are known as 'dispatch down' of wind power [1].

Studies concerned with accommodating large penetrations of renewables and decarbonising power systems show the need to avoid curtailment, by making use of excess wind power, for example by charging electrical energy storage systems [2-5].

Wind curtailment already occurs on the power system of the Republic of Ireland and Northern Ireland (the "All-island" power system). 2.2\% of total available wind output (119 GWh) was dispatched down in 2011, with an estimated 80\% due to curtailment [1]. In 2012, dispatch down was $2.1 \%[6]$.

In 2013, 16\% of the All-island electricity demand was supplied by $2395 \mathrm{MW}$ of wind power [7]. Going forward, the All-island system has a target for $40 \%$ of electricity to be generated by renewables by 2020 [8,9] with 37\% expected to be met by wind power - the highest target within the EU. The installed wind capacity required to meet this target depends on how much wind power is curtailed, so there is an interest in estimating future levels of curtailment, as well as investigating measures to reduce it.

There are numerous studies that estimate potential curtailment on the 2020 All-island system. These can be differentiated between the early studies that assumed pre-recession demand growth estimates which found curtailment not to be an issue in 2020 [10-13], and the later study by Mc Marrigle et al. that used post-recession demand growth estimates and which found the potential for curtailment in 2020 to be considerable [14].

The authors have previously contributed to this literature [15] by estimating potential curtailment on the All-island system with results consistent 
with those of Mc Garrigle et al. This paper builds on this work by estimating the installed wind capacity required to meet the $37 \%$ demand target. Furthermore, the paper extends the model to estimate the potential impact of electrical energy storage on reducing curtailment. Finally, the model has been adapted to MS Excel and made available as a free open-source model for download [16].

\section{Description of the model}

The model developed for the authors' previous paper [15] consists of a component to estimate aggregated hourly wind output based on hourly wind speed data from 51 grid nodes around the island, and a component to estimate curtailment based on hourly wind power output and demand data and a set of curtailment rules based on the published rules that govern which conventional generators need to be kept on-line for system security reasons.

The model presented here is an enhanced version of the previous one. In particular, to estimate the potential for electrical energy storage to reduce curtailment, a wholesale electricity market is modelled to provide a price signal for the storage to respond to. The market is modelled using a simplified representation of a supply mix where generation is dispatched in the following merit order: wind, baseload, mid-merit, peaking plant. Market prices are estimated based on assumed marginal costs of generation. Prices are lowest when wind power is being curtailed and highest when peaking plant is used. Note this is not intended to provide an accurate simulation of the supply-mix and dispatch of the All-island power system and single electricity market. It is used simply to provide a price signal with an appropriate shape such that the storage system operates in a manner that increases its profits, while also achieving a reduction in curtailment. The following describes the model calculations in detail.

\subsection{Wind power and demand}

The four years of hourly demand data and national wind power capacity factors that were calculated in the previous paper [15] for the years 2009 through to 2012 are re-used here. To estimate 2020 values, the installed wind capacity and demand are scaled up appropriately (17\% in the case of the demand). All data and results are all-island values.

The net demand $P_{N e t}$ is calculated from the system demand $\left(P_{D}\right)$ and wind output $\left(P_{W}\right)$ as:

$P_{N e t}=P_{D}-P_{W}$

\subsection{Curtailment}

Curtailment is estimated based on two curtailment rules. The first rule estimates curtailment based on the requirement to ensure minimum levels of synchronous generation. The second rule estimates curtailment based on the requirement to limit the system non-synchronous penetration. In the model, the curtailment required for the two rules are calculated separately, and the actual curtailment in any one time step is taken as the maximum of the two. The rules are fully described in the previous paper [15], while the following focusses on their implementation.

For rule 1, the required minimum synchronous generation $\left(P_{\text {Minsyngen }}\right)$ is $2503 \mathrm{MW}, 2258 \mathrm{MW}$, and $2416 \mathrm{MW}$ for week daytime, weekend daytime, and night-time respectively, multiplied by a partial load factor $\lambda$ of $50 \%$. Curtailment required for rule $1\left(P_{\text {Curt } 1}\right)$ is calculated as:

$P_{\text {Curt } 1}=\max \left(0, P_{\text {MinsynGen }}-P_{\text {Net }}\right)$

For rule 2, the system non-synchronous penetration $(\beta)$ is defined as [14]:

$\beta=\frac{P_{W}+P_{I m p}}{P_{D}+P_{E x p}}$

Where $P_{I m p}$ and $P_{E x p}$ are interconnector imports and exports respectively. Imports are not included in the model, so the curtailment required for rule 2 $\left(P_{\text {Curt } 2}\right)$ is calculated using the system nonsynchronous penetration limit $\beta_{\text {Lim }}$ as:

$P_{\text {Curt } 2}=\max \left(0, P_{W}-\beta_{\text {Lim }}\left[P_{D}+P_{E x p}\right]\right)$

Interconnectors can be used to reduce curtailment by exporting power to interconnected neighbouring power systems [11]. $1 \mathrm{GW}$ of interconnection is expected between the All-island and GB power systems in 2020 [14]. The model takes into account the potential use of interconnectors to reduce curtailment as follows. The curtailment required for rule 1 can be reduced to the level $\left(P_{\text {Curt1,Int }}\right)$ by exporting power on the interconnector $\left(P_{\operatorname{Exp} 1}\right)$ up to a limit set by its capacity $\left(P_{\text {Int }}\right)$.

$P_{\text {Exp } 1}=\min \left(P_{\text {Curt } 1}, P_{\text {Int }}\right)$

$P_{\text {Curt } 1, I n t}=P_{\text {Curt } 1}-P_{\text {Exp } 1}$

Similarly, curtailment required for rule 2 can be reduced to the level $P_{\text {Curt2,Int }}$ given exported power $P_{\text {Exp2 }}$.

$P_{\text {Exp2 }}=\min \left(P_{\text {Curt } 2} / \beta_{\text {Lim }}, P_{\text {Int }}\right)$

$P_{\text {Curt } 2 \text { Int }}=\max \left(0, P_{W}-\beta_{\text {Lim }}\left[P_{D}+P_{\text {Exp } 2}\right]\right)$

The relationship between the system nonsynchronous penetration and interconnection exports are accounted for in equations (8) and (9). 
Note that this was not accounted for in the previous paper. The impact of this is described in the results.

The actual amounts of curtailment $\left(P_{\text {Curt }}\right)$ and export $\left(P_{\text {Exp }}\right)$ required is given as the maximum of the two rules:

$$
\begin{aligned}
& P_{\text {Curt }}=\max \left(P_{\text {Curt } 1, \text { Int }}, P_{\text {Curt } 2, \text { Int }}\right) \\
& P_{\text {Exp }}=\max \left(P_{\text {Exp } 1}, P_{\text {Exp } 2}\right)
\end{aligned}
$$

\subsection{Dispatch of generation}

The modified net demand $P_{\text {ModNet }}$ is calculated as:

$P_{\text {ModNet }}=P_{D}+P_{\text {Exp }}-\left(P_{W}-P_{\text {Curt }}\right)$

The modified net demand is met by the supply mix shown in Table 1. The method for dispatching generation and modelling the wholesale electricity market is based on work by Grünewald [17], who developed a model of the GB wholesale electricity market to estimate the commercial viability of electrical energy storage on the GB power system with high penetrations of wind power. A capacity margin is specified such that the total capacity thermal plant (baseload, mid-merit and peaking) exceeds the peak demand by $20 \%$.

\begin{tabular}{|l|l|l|l|}
\hline $\begin{array}{l}\text { Generation } \\
\text { type }\end{array}$ & $\begin{array}{l}\text { Share of } \\
\text { conventional } \\
\text { generation (\%) }\end{array}$ & $\begin{array}{l}\text { Merit } \\
\text { order } \\
(g)\end{array}$ & $\begin{array}{l}\text { Marginal } \\
\text { cost, } \\
(£ / \mathrm{kWh})\end{array}$ \\
\hline Wind & $\begin{array}{l}\text { Specified by } \\
\text { user }\end{array}$ & 1 & 0 \\
\hline Baseload & $15 \%$ & 2 & 8 \\
\hline Mid-merit & $55 \%$ & 3 & 20 \\
\hline Peaking & $30 \%$ & 4 & 100 \\
\hline
\end{tabular}

Table 1 - supply mix, merit order and marginal costs used in the model.

\subsection{Wholesale electricity market}

The wholesale electricity price $\Pi$ is estimated depending on the current merit-order position. If wind is being curtailed:

$\Pi=\dot{\pi}_{g} \times\left[1+\kappa \times e^{-\alpha\left(\frac{P_{W}-P_{C u r t}}{P_{W}}\right)}\right]$

Else if peaking plant are generating:

$\Pi=\dot{\pi}_{g} \times\left[1+\kappa \times e^{-\alpha\left(\frac{C_{g}-P g}{C_{g}}\right)}\right]$

Otherwise:

$\Pi=\dot{\pi}_{g} \times\left[1+\frac{\dot{\pi}_{g+1}-\dot{\pi}_{g}}{\dot{\pi}_{g}} \frac{P_{g}}{C_{g}}\right]$

Where $\dot{\pi}_{g}, C_{g}$ and $P_{g}$ are the marginal cost of generation, installed capacity and power output of the plant in the current merit-order. $\kappa$ and $\alpha$ provide the price curve with an appropriate shape. Similar to [17] a value of 50 was chosen for $\kappa$ and 5 for $\alpha$. Table 1 shows the marginal costs that were used.

\subsection{Operation of storage}

The control strategy for the storage system is based on work by Barton et al. on modelling storage within the FESA system balancing model for GB $[18,19]$. The main difference is that here price is used as the control signal for storage while in FESA net demand is used as the control signal.

Broadly, the objective of the storage control strategy is that the rate of charge or discharge of the storage depends on its state of charge, as well as the relative prices in the wholesale electricity market.

In particular, the storage is charged or discharged depending on the price in hour $t\left(\pi_{t}\right)$ and the 24hour average price $\left(\bar{\pi}_{t}\right)$. As illustrated by the $\mathrm{x}$-axis in Figure 1, the storage discharges when $\pi_{t}$ is greater than $\bar{\pi}_{t}$, and charges when $\pi_{t}$ is smaller than $\bar{\pi}_{t}$.

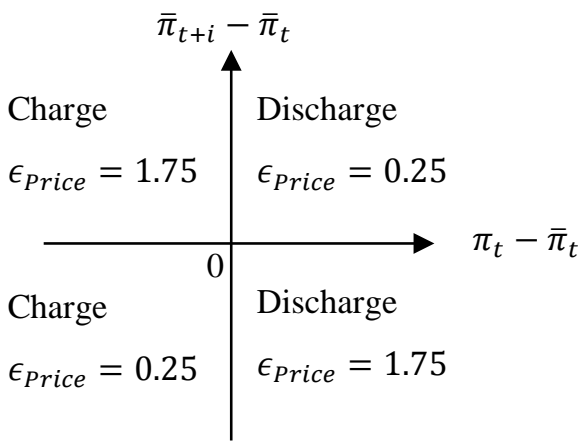

Figure 1 - Relationship between price, decision to charge or discharge, and price scaling factor.

The rate of charge or discharge $\left(P_{\text {Stor }}\right)$ depends on its rated power capacity $\left(P_{\text {Rated }}\right)$, discharge efficiency $\left(\eta_{\text {Dis }}\right)$, a price scaling factor $\left(\epsilon_{\text {Price }}\right)$ and storage state of charge scaling factor $\left(\epsilon_{S O C}\right)$.

$P_{\text {Stor }}=$
$\left\{\begin{array}{c}\min \left(P_{\text {Rated }}, \epsilon_{\text {Price }} \epsilon_{\text {SoC }} P_{\text {Rated }}\right) \text { if } \pi_{t}<\bar{\pi}_{t} \\ \max \left(-\eta_{\text {Dis }} P_{\text {Rated }},-\epsilon_{\text {Price }} \epsilon_{\text {SOC }} P_{\text {Rated }}\right) \text { if } \pi_{t}>\bar{\pi}_{t}\end{array}\right.$

Figure 1 illustrates the relationship between the price and the price scaling factor along the y-axis. The 24-hour average price $\bar{\pi}_{t}$ is compared with the average of $\bar{\pi}_{t}$ over future $i$ number of hours $\left(\bar{\pi}_{t+i}\right)$.

$\bar{\pi}_{t+i}=\frac{\sum_{n}^{i} \bar{\pi}_{t}}{i}$

When $\bar{\pi}_{t+i}$ is greater than $\bar{\pi}_{t}$ discharging is scaled down and charging scaled up. When $\bar{\pi}_{t+i}$ is smaller than $\bar{\pi}_{t}$ discharging is scaled up and charging scaled down. Factors of 1.75 and 0.25 are used here 
for scaling up and down respectively, and $i$ is 8 hours.

Figure 2 illustrates the relationship between state of charge $\left(E_{S O C}\right)$ and the state of charge scaling factor $\left(\epsilon_{S O C}\right)$, where $E_{\text {Rated }}$ is the rated storage energy capacity. The scaling factor increases linearly with state of charge when discharging and decreases linearly with state of charge when charging. The relationship is calibrated such that the storage tends towards a state of half charge.

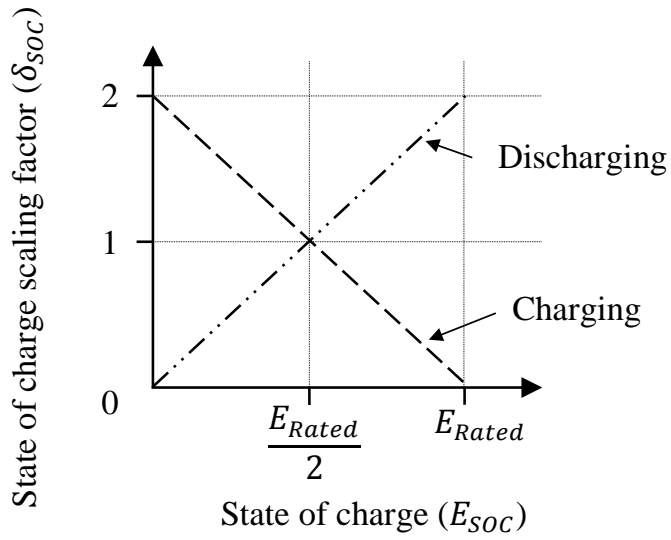

Figure 2 - Relationship between state of charge and state of charge scaling factor.

The net energy flow to the storage $\left(E_{S t o r}\right)$ depends on the net power flow $\left(P_{S t o r}\right)$, charging efficiency $\left(\eta_{\text {Char }}\right)$ and discharging efficiency $\left(\eta_{\text {Dis }}\right)$.

$E_{\text {Stor }}=\left\{\begin{array}{c}\eta_{\text {Char }} P_{\text {Stor }} \text { if } P_{\text {Stor }}>0 \\ \frac{P_{\text {Stor }}}{\eta_{\text {Dis }}} \text { if } P_{\text {Stor }}<0\end{array}\right.$

\section{Results}

Figure 3 shows mean curtailment results with $500 \mathrm{MW}$ of interconnection for the 4 years of data. Whiskers extend to show differences between the results published in the previous paper [15]. The results presented here show higher levels of curtailment for system non-synchronous penetration limits of $50 \%$ and $60 \%$, with negligible differences for $75 \%$. As discussed previously, this is because the effect of interconnection on system non-synchronous penetration was not accounted for previously. The All-island system non-synchronous penetration limit is $50 \%$ at present, with a limit of $75 \%$ expected to be technically feasible in 2020 [20]. A SNSP limit of $75 \%$ is used in the results that follow.

Figure 4 shows the amount of demand met by wind against installed wind capacity given $500 \mathrm{MW}$ interconnection, 75\% SNSP and no storage. Values shown are the mean for the 4 years data with whiskers extending to values for the maximum and minimum years. The target of $37 \%$ is indicated for clarity. On average over the four years of data, which had a mean wind capacity factor of $27.6 \%$, the target is met by just under $7.5 \mathrm{GW}$ of installed wind capacity. For the year with lowest wind output (2010, capacity factor $23.31 \%$ ) the results indicate a requirement for over $9 \mathrm{GW}$ of installed wind capacity. The year with highest wind output (2009, capacity factor $31.46 \%$ ) requires just over $6 \mathrm{GW}$.

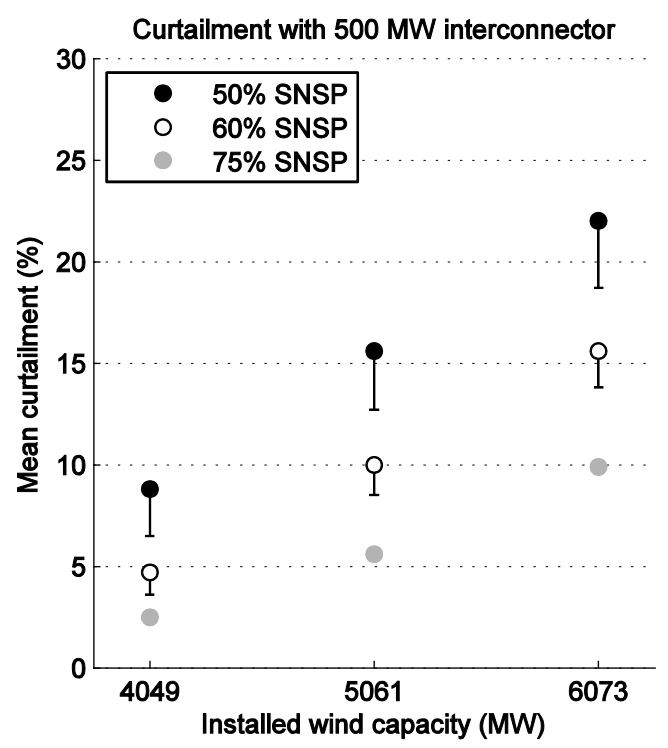

Figure 3 - Curtailment results with $500 \mathrm{MW}$ of interconnection.

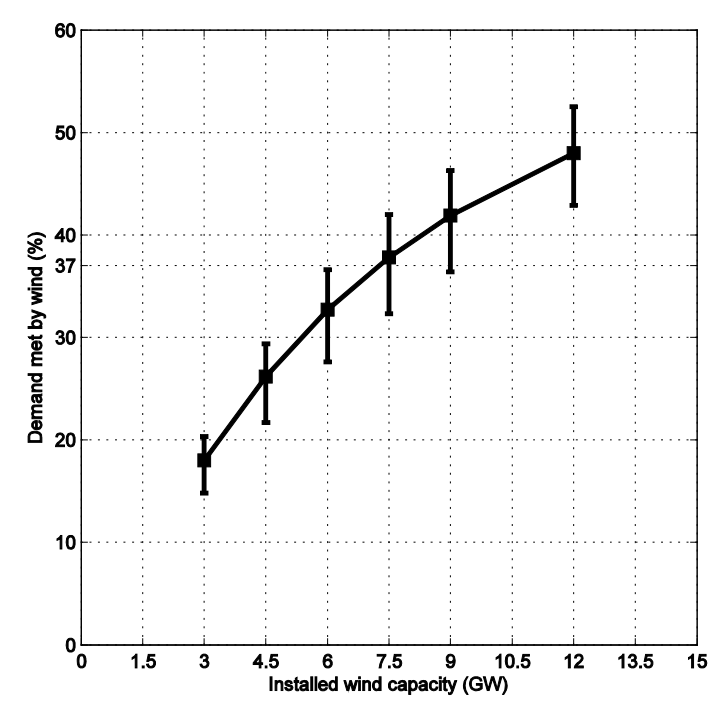

Figure 4 - Percentage demand met by wind with $500 \mathrm{MW}$ interconnector, 75\% SNSP and no storage. 
Figure 5 shows the effect of storage on the reduction in installed wind capacity required to meet the $37 \%$ target. Values are shown with and without $500 \mathrm{MW}$ of interconnection and, as above, are mean values with whiskers showing maximum and minimum reductions. The storage is characterised by a duration of 8 hours, 100\% depth of discharge, and a round trip efficiency of $85 \%$. On average, $500 \mathrm{MW}$ of storage displaces $266 \mathrm{MW}$ of wind power with no interconnection, and $129 \mathrm{MW}$ with $500 \mathrm{MW}$ of interconnection. Diminishing returns apply: adding an additional $500 \mathrm{MW}$ of storage to the above displaces an additional $106 \mathrm{MW}$ and $53 \mathrm{MW}$ of wind power respectively.

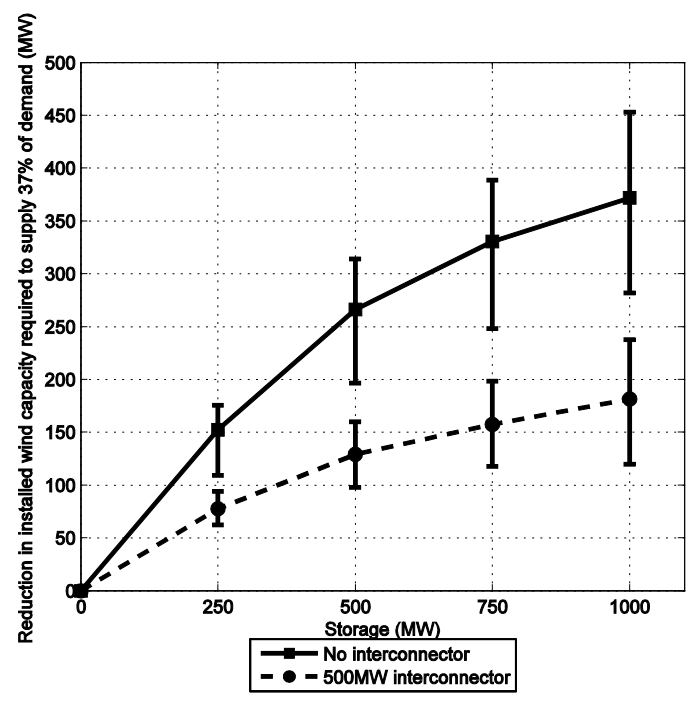

Figure 5 - Effect of storage on reduction in installed wind capacity required to meet $37 \%$ of demand. Storage duration is 8 hours, SNSP 75\%.

\section{Discussion and conclusions}

McGarrigle et al. estimated 6262 MW of installed wind capacity would be required to meet $37 \%$ of demand [14], for a 'low' offshore scenario (25 MW) which is comparable to the scenario used here (we assume no offshore wind capacity). While this is within the range of $6 \mathrm{GW}$ to $9 \mathrm{GW}$ presented here, it is considerably lower than the mean of nearly $7.5 \mathrm{GW}$. One possible explanation is that McGarrigle et al. assume 950 MW of interconnection with GB, while $500 \mathrm{MW}$ is used here. Furthermore it should be noted that McGarrigle et al. use a mixed integer unit commitment and economic dispatch model which is more sophisticated than the model used here; discrepancies between the two models should be expected.
It is the ambition of the authors to continue developing the model, for example by calibrating the dispatch of generation and wholesale electricity market so that they are more representative of the All-island system. Nonetheless, the model already serves as a tool for exploring methods of reducing curtailment on the All-island system; this paper has presented an initial example that illustrates some of the capability of the model.

The model has been developed in MS Excel and made available to download for free [16]. This is to encourage and support further research on this subject, promote transparency and scrutiny of research methods, and ultimately allow for improved versions of the model in future. Feedback is welcome and comments can be sent to the corresponding author.

\section{Acknowledgements}

This work was supported by the Engineering and Physical Sciences Research Council, UK, within the Integrated, Market-fit and Affordable Gridscale Energy Storage (IMAGES) project (EP/K002228/1) and within the Transformation of the Top and Tail of Energy Networks project (EP/I031707/1). The authors gratefully acknowledge data from the UK Meteorological Office, the National Centers for Environmental Prediction, Eirgrid Group, and the Irish Single Electricity Market Operator.

\section{References}

[1] Eirgrid, SONI, 2012., 2011 Curtailment Report. Accessed 4th July 2013. Available from: http://www.eirgrid.com/media/2011\%20Curtailmen t\%20Report.pdf.

[2] Delucchi, M.A., Jacobson, M.Z., 2011, Providing all global energy with wind, water, and solar power, Part II: Reliability, system and transmission costs, and policies. Energy Policy, 39, 1170-1190.

[3] Elliston, B., Diesendorf, M., MacGill, I., 2012, Simulations of scenarios with $100 \%$ renewable electricity in the Australian National Electricity Market. Energy Policy, 45, 606-613.

[4] Budischak, C., Sewell, D., Thomson, H., Mach, L., Veron, D.E., Kempton, W., 2013, Costminimized combinations of wind power, solar power and electrochemical storage, powering the grid up to $99.9 \%$ of the time. Journal of Power Sources, 225, 60-74. 
[5] Rasmussen, M.G., Andresen, G.B., Greiner, M., 2012, Storage and balancing synergies in a fully or highly renewable pan-European power system. Energy Policy, 51, 642-651.

[6] Eirgrid, SONI, 2013., 2012 Curtailment Report. Accessed 16th September 2013. Available from: http://www.eirgrid.com/media/2012_Curtailment Report.pdf.

[7] Eirgrid, 2014., Annual Report 2013. Accessed 2 June 2014. Available from: http://www.eirgrid.com/aboutus/publications/.

[8] Department of Communications, Energy and Natural Resources, 2010., National Renewable Energy Action Plan. Accessed 11th September 2013. Available from: http://www.dcenr.gov.ie/NR/rdonlyres/03DBA6CF -AD04-4ED3-B443B9F63DF7FC07/0/IrelandNREAPv11Oct2010.pdf.

[9] Department of Enterprise, Trade and Investment, 2010., Energy: a strategic framework for Northern Ireland. Accessed 11th September 2013. Available from: http://www.detini.gov.uk/strategic energy_framew ork sef 2010_-3.pdf.

[10] Tuohy, A., O'Malley, M., 2009. Impact of pumped storage on power systems with increasing wind penetration, In: Power \& Energy Society General Meeting, 2009. PES '09. IEEE, Anonymous pp. 1-8.

[11] Denny, E., Tuohy, A., Meibom, P., Keane, A., Flynn, D., Mullane, A., et al., 2010, The impact of increased interconnection on electricity systems with large penetrations of wind generation: A case study of Ireland and Great Britain. Energy Policy, 38, 6946-6954.

[12] Meibom, P., 2007., Final Report for All Island Grid Study. Work-stream 2(b): Wind Variability Management Studies. Accessed 16th September 2013. Available from: http://www.eirgrid.com/media/Workstream\%202B. pdf.

[13] Doherty, R., 2008., All Island Grid Study. Workstream 2A: High level assessment of suitable generation portfolios for the All-island system in 2020. Accessed 16th September 2013. Available from:

http://www.eirgrid.com/media/Workstream\%202A. pdf.
[14] Mc Garrigle, E.V., Deane, J.P., Leahy, P.G., 2013, How much wind energy will be curtailed on the 2020 Irish power system? Renewable Energy, 55, 544-553.

[15] McKenna, E., Grünewald, P., Thomson, M., 2014, Going with the wind: temporal characteristics of potential wind curtailment in Ireland in 2020 and opportunities for demand response (in press). Available from https://dspace.lboro.ac.uk/2134/13302. IET Renewable Power Generation.

[16] McKenna, E., Thomson, M., 2014., Electricity System Balancing and Market (ESBM) model. Available from: https://dspace.lboro.ac.uk/2134/14810.

[17] Grünewald, P., Cockerill, T., Contestabile, M., Pearson, P., 2011, The role of large scale storage in a GB low carbon energy future: Issues and policy challenges. Energy Policy, 39, 4807-4815.

[18] Barton, J., Huang, S., Infield, D., Leach, M., Ogunkunle, D., Torriti, J., et al., 2013, The evolution of electricity demand and the role for demand side participation, in buildings and transport. Energy Policy, 52, 85-102.

[19] Barnacle, M., Robertson, E., Galloway, S., Barton, J., Ault, G., 2013, Modelling generation and infrastructure requirements for transition pathways. Energy Policy, 52, 60-75.

[20] Ecofys, 2010., All island TSO facilitation of renewables studies. Accessed 11th September 2013. . Available from: http://www.ecofys.com/files/files/faciltiation_of_re nwables_wp3_final_report.pdf. 